\title{
COMPARATIVE STUDY OF TRANSVAGINAL ULTRASOUND WITH HISTOPATHOLOGY IN DIAGNOSING ENDOMETRIAL PATHOLOGY IN POSTMENOPAUSAL BLEEDING
}

\author{
Sreelakshmy Krishnankutty Nair1, Rema Velayuthan Nair², Anitha Rajendran³, Dhyan Sumathi ${ }^{4}$, Adarsh Suresh Kumar ${ }^{5}$ \\ ${ }_{1}^{1}$ Assistant Professor, Department of Obstetrics and Gynaecology, Sree Mookambika Institute of Medical Sciences. \\ 2 Professor, Department of Obstetrics and Gynaecology, Sree Mookambika Institute of Medical Sciences. \\ ${ }^{3}$ Postgraduate Trainee, Department of Obstetrics and Gynaecology, Sree Mookambika Institute of Medical Sciences. \\ ${ }^{4}$ Intern, Department of Obstetrics and Gynaecology, Sree Mookambika Institute of Medical Sciences. \\ IIntern, Department of Obstetrics and Gynaecology, Sree Mookambika Institute of Medical Sciences.
}

\section{ABSTRACT}

\section{BACKGROUND}

Endometrial biopsy is considered the standard for detecting endometrial pathology, but since it is an invasive and blind procedure transvaginal ultrasound has been recommended as a less invasive substitute for detecting endometrial disease.

\section{METHODS}

This cross-sectional study was done in 100 patients to evaluate the efficacy of transvaginal ultrasound as a non-invasive investigative procedure for excluding endometrial pathology in patients with postmenopausal bleeding. All these patients underwent transvaginal sonography and dilatation and curettage.

\section{RESULTS}

In diagnosing endometrial pathology transvaginal sonography showed a sensitivity of $71.79 \%$, specificity of $100 \%$, positive predictive value of $100 \%$ and negative predictive value of $50 \%$. A cut-off of $4 \mathrm{~mm}$ endometrial thickness was taken for defining normality. No cases of endometrial malignancy were missed when $4 \mathrm{~mm}$ was taken as the cut-off. The sensitivity of transvaginal sonography in detecting premalignant lesions was $75.76 \%$, specificity was $82.35 \%$, positive predictive value was $89.29 \%$ and negative predictive value was $63.64 \%$.

\section{CONCLUSION}

The study concludes that transvaginal sonographic measurement of endometrial thickness can be used to exclude endometrial pathology in postmenopausal bleeding.

\section{KEYWORDS}

Dilatation And Curettage, Transvaginal Ultrasound, Endometrial Biopsy, Endometrial Thickness.

HOW TO CITE THIS ARTICLE: Nair SK, Nair RV, Rajendran A, et al. Comparative study of transvaginal ultrasound with histopathology in diagnosing endometrial pathology in postmenopausal bleeding. J. Evolution Med. Dent. Sci. 2016;5(14):640-642, DOI: $10.14260 /$ jemds/2016/147

\section{INTRODUCTION}

In the last three decades there has been an increase in the incidence of endometrial adenocarcinoma. ${ }^{1}$ Incidence in India is $4.3 / 100000 .^{2}$ It is the most common gynaecological malignancy and fourth most common cancer in women in United States. ${ }^{3}$ In developing countries it is the second most common gynaecological malignancy with incidence of $5.9 / 100000.4$ Overall about $2-3 \%$ of women develop endometrial cancer in their lifetime. ${ }^{3}$ In $85 \%$ cases postmenopausal women are affected. 5 Peak incidence is between the sixth and seventh decade of life with the mean age of patients being $65 \mathrm{yrs} .{ }^{6}$ Most cases (75\%) are diagnosed very early (FIGO-STAGE 1) due to early episodes of abnormal uterine bleeding occurring in over $90 \%$ cases. $^{7}$

Majority of post-menopausal vaginal bleeding is secondary to atrophic changes of endometrium or vagina. ${ }^{7}$

Financial or Other, Competing Interest: None.

Submission 05-01-2016, Peer Review 30-01-2016,

Acceptance 05-02-2016, Published 17-02-2016.

Corresponding Author:

Dr. Sreelakshmy Krishnankutty Nair,

Himadri, GNRA 49G, Melarannur,

Karamana P.O., Trivandrum-695002.

E-mail: sreelakhmy@yahoo.com

DOI: $10.14260 /$ jemds/2016/147
Only $10 \%$ patients with postmenopausal bleeding have endometrial carcinoma depending on age and other risk factors. $^{7}$ The other causes of post-menopausal bleeding include endometrial atrophy $(60-80 \%)$ in which vessels become fragile and breakup, endometrial polyps (2-12\%), endometrial hyperplasia (5-10\%). ${ }^{7}$

Curettage of uterine cavity under general anaesthesia is the gold standard for identifying endometrial pathology. ${ }^{1}$ But considering the above mentioned figures, this examination is often unnecessary, expensive, invasive and involves considerable risks. ${ }^{1}$ Two to ten percent false negative rates have also been reported, especially in cases with focal lesions.8,9,10 Transvaginal ultrasound with measurement of endometrial thickness exhibits good accuracy in differentiating normal and abnormal endometrium when compared with histological findings from uterine cavity. ${ }^{1}$

The finding of endometrial thickness more than $4 \mathrm{~mm}$, a polypoidal endometrial mass requires further evaluation. ${ }^{7}$ Prospective study shows that an endometrial thickness less than $4 \mathrm{~mm}$ in a post-menopausal woman with bleeding will have an incidence of endometrial carcinoma of only $1 / 10000.11$

Sonography may also identify abnormal structural changes in the endometrium. Cystic endometrial changes 
suggest polyps, homogeneously thickened endometrium may indicate hyperplasia and heterogeneous structural pattern is suspicious of malignancy. ${ }^{12}$

Hence, curettage could be avoided in post-menopausal women with bleeding and endometrial thickness less than $5 \mathrm{~mm}$ and still not miss any endometrial cancer. This may reduce the number of $\mathrm{D}$ and $\mathrm{C}$ by $70 \% .13$ This study plans to evaluate patients with postmenopausal bleeding using transvaginal sonography and fractional curettage. The study aims to determine whether transvaginal sonography can be used as a less invasive diagnostic tool instead of endometrial biopsy in post-menopausal bleeding.

\section{MATERIALS AND METHODS}

This is a cross-sectional study conducted in 100 consecutive patients with postmenopausal bleeding attending the outpatient clinic of the Department of OBG of a tertiary care medical college hospital. The study period was from August 2014 to May 2015. Convenient sampling technique was used. These patients were recruited into the study after written informed consent based on the following criteria- absence of menstrual bleeding for six months, abnormal uterine bleeding. All patients with use of hormone replacement therapy/Tamoxifen were excluded. The study was started after getting ethical approval from the institution ethics committee.

Transvaginal sonography was performed using Ultrasound scanner provided with $5 \mathrm{MHz}$ TVS probe. Endometrial thickness was taken in order to evaluate the extent to which it excluded the presence of endometrial lesions; $4 \mathrm{~mm}$ endometrial thickness was taken as a cut-off for this. Multiple sagittal and transverse planes through the uterine fundus and lower segment were taken to find the thickest area. Sonographic criteria put forward by Fleischer and Colleagues. ${ }^{14}$ tell that endometrium appears at the center of the uterus as an hyperechoic structure or group of hyperechoic interfaces clearly separated from hypoechoic myometrium. Another important consideration taken was texture of the endometrium.

Atrophic endometrium will appear in ultrasound as a thin pencil like echogenicity surrounded by an intact hypoechoic halo. The normal endometrium has homogeneous echotexture and regular interface with myometrium. Vacuolation, non-homogeneous echotexture. ${ }^{2}$ irregularity of endomyometrial interface indicate abnormality. ${ }^{15}$ When fluid was present in the uterine cavity, size of the anechoic area was subtracted from the total thickness. Patients with suboptimal visualization of endometrium were excluded from the study group. All patients underwent fractional curettage under general anaesthesia. The tissue obtained was sent for examination to the Department of Pathology.

Data was recorded and mean and standard deviations were calculated for demographic factors. The diagnostic accuracy of transvaginal sonography in excluding or identifying endometrial lesion was found by calculating sensitivity, specificity, positive and negative predictive values each within its 95\% confidence interval. The data was analysed using statistical package for social services version 20 for windows.

\section{RESULTS}

A total of 146 patients were screened for the study. Seventeen patients did not consent for the study and were excluded, a further 23 were excluded as they did not meet the inclusion criteria and 6 patients who received hormone replacement were also kept out. Thus the final study recruited 100 patients, Histopathological Examination (HPE) findings of the endometrium showed normal endometrium in $22 \%$ cases, $4 \%$ had benign lesions and $8 \%$ had endometrial polyps. Endometrial malignant and premalignant lesions accounted for $66 \%$ cases of postmenopausal bleeding (Table 1 ).

\begin{tabular}{|c|c|}
\hline Histopathological Findings & Percentage \\
\hline Normal Endometrium & 22 \\
\hline Endometrial Benign Lesions & 4 \\
\hline Endometrial Polyp & 8 \\
\hline Premalignant Lesions & 63 \\
\hline Malignant Lesions & 3 \\
\hline Total & $\mathbf{1 0 0}$ \\
\hline Table
\end{tabular}

Table 1: Histopathological Examination (HPE) Findings

The comparison of histopathological findings with endometrial thickness assessed by TVS taking $4 \mathrm{~mm}$ as the cutoff revealed that the diagnosis was accurate in 78 cases $(22$ true negative diagnoses and 56 true positive diagnoses). There were no false positives and false negatives were 22 , but this did not include any case of endometrial adenocarcinoma. Sensitivity of TVS in diagnosing endometrial pathology is $71.79 \%$ and specificity was 100\%. (Table 3) Positive predictive value was $100 \%$ and negative predictive value is 50\%. (Table 2) Transvaginal sonography detected premalignant and malignant cases in 50 out of 66 cases; this included 3 cases of endometrial adenocarcinoma. There were 6 false positive cases and 16 false negative cases. Numbers of true negatives were 28 . The sensitivity $75.76 \%$, specificity was $82.35 \%$ with a positive predictive value $89.29 \%$ and negative predictive value $63.64 \%$ (Table 3 ).

\begin{tabular}{|c|c|c|c|}
\hline HPE Findings & $\mathbf{N}$ & $\begin{array}{c}\text { Less than or } \\
\text { equal to } \\
\mathbf{4 m m}\end{array}$ & $\begin{array}{c}\text { More } \\
\text { than 4mm }\end{array}$ \\
\hline $\begin{array}{c}\text { Normal } \\
\text { Endometrium }\end{array}$ & 22 & 22 & - \\
\hline $\begin{array}{c}\text { Endometrial Benign } \\
\text { Lesions }\end{array}$ & 4 & 2 & 2 \\
\hline Endometrial Polyp & 8 & 4 & 4 \\
\hline $\begin{array}{c}\text { Endometrial } \\
\text { Premalignant Lesions }\end{array}$ & 63 & 16 & 47 \\
\hline Malignant Lesions & 3 & & 3 \\
\hline \multicolumn{2}{|c|}{$\mathbf{4 4}$} & $\mathbf{5 6}$ \\
\hline Total & $\mathbf{1 0 0}$ & $\mathbf{4 4}$ \\
\hline Table 2: HPE versus Transvaginal Sonographic \\
assessment of Endometrial Thickness
\end{tabular}

\begin{tabular}{|c|c|c|c|c|}
\hline Variable & Sensitivity \% & Specificity \% & +ve Predictive Value & -ve Predictive Value \\
\hline $\begin{array}{c}\text { Prediction of Endometrial } \\
\text { Lesions }\end{array}$ & $71.79 \%$ & $100 \%$ & $100 \%$ & $50 \%$ \\
\hline $\begin{array}{c}\text { Prediction of Endometrial } \\
\text { Premalignant and Malignant } \\
\text { Lesions }\end{array}$ & $75.76 \%$ & $82.35 \%$ & $89.29 \%$ & $63.64 \%$ \\
\hline \multicolumn{4}{|c}{ Table 3: Diagnostic Accuracy of TVS assessment of Endometrial Thickness } \\
\hline
\end{tabular}




\section{DISCUSSION}

Endometrial curetting or sampling is considered the gold standard for evaluating patients with postmenopausal bleeding. Transvaginal sonographic measurement of endometrial thickness is being used by various investigators as an ideal non-invasive technique in postmenopausal bleeding to identify patients who need further invasive diagnostic procedures. But transvaginal sonography cannot differentiate between hyperplasia, endometrial polyps and malignant lesions. ${ }^{16,17}$ some studies shows a difference in sensitivity of $8.9 \%$ between sonographic and histological diagnosis of endometrial carcinoma. ${ }^{16,18}$

In our study group, no cases of endometrial carcinoma were missed by transvaginal sonography when $4 \mathrm{~mm}$ was taken as the cut-off. In a study by Doruman and Colleagues when the cut-off was taken as $5 \mathrm{~mm}, 3$ endometrial malignancies were missed out of 15 identified by endometrial sampling. ${ }^{19}$ In our study group, post-menopausal bleeding was not due to any endometrial pathology in $22 \%$ cases. All these cases were correctly identified by Transvaginal sonography. These patients were unnecessarily submitted to D and C. Despite the high specificity (100\%) in excluding endometrial pathology the sensitivity was $71.79 \%$. The relatively low sensitivity is due to high false negative values and which included 16 cases of endometrial hyperplasia without atypia.

\section{CONCLUSION}

These results show that transvaginal sonography is an efficient, non-invasive method to exclude endometrial pathology. No case of endometrial carcinoma was missed when $4 \mathrm{~mm}$ was taken as the cut-off. Our study like other previous studies emphasizes the role of measuring endometrial thickness by transvaginal sonography in all cases of postmenopausal bleeding thereby limiting the use of invasive procedures.

\section{REFERENCES}

1. Conoscenti G, Meir YJ, Fischer-Tamaro L, et al. Endometrial assessment by transvaginal sonography and histological findings after $\mathrm{D}$ and $\mathrm{C}$ in women with postmenopausal bleeding. Ultrasound Obstet Gynecol 1995;6:108-115.

2. Balasubramaniam G, Sushma S, Rasika B, et al. Hospitalbased study of endometrial cancer survival in Mumbai, India. Asian Pac J Cancer Prev 2013;14:977-80.

3. Seigal R, Ma J, Zou Z, et al. Cancer statistics. CA Cancer J Clin 2014;64:9-29.

4. Faria SC, Sagebiel T, Balachandran A, et al. Imaging in endometrial carcinoma. Indian J of Radiol Imaging 2015 Apr-Jun; 25(2):137-147.
5. Seigel R, Ward E, Bravley O, et al. Cancer statistics. CA Cancer J Clin 2011;61:212.

6. Arora V, Quinn MA. Endometrial cancer. Best Pract Res Clin Obstet Gynaecol 2012;26:311-24.

7. Dowdy SC, Mariani A, Lurain JR. Uterine cancer. In: Berek, editor. Berek and Novak's Gynaecology, $15^{\text {th }}$ edition. New Delhi: Wolters Kluwer Health India Pvt Ltd; 2013. p. $1250-1303$.

8. Stovall TG, Solomon SK, Ling FW. Endometrial sampling prior to hysterectomy. Obstet Gynecol 1989;73:405-9.

9. Altaras MM, Aviram R, Cohen I, et al. Microhysterectomy and endometrial biopsy results following failed diagnostic dilatation and curettage in women with postmenopausal bleeding. Int J Gynecol Obstet 1993; 42:255-60.

10. Word B, Gravlee L, Widerman G. The fallacy of simple uterine curettage. Obstet Gynecol 1958;12:642-7.

11. Goldstein SR. The role of transvaginal ultrasound or endometrial biopsy in the evaluation of menopausal endometrium. 2009;201(1): Pg 5-11.

12. Miller DS, Schorge JO. Endometrial cancer. Williams Gynaecology. 2nd edition. Texas: McGraw Hill; 2008; p 821.

13. Granberg S, Wikland M, Karlsson B, et al. Endometrial thickness measured by endovaginal ultrasonography for identifying endometrial abnormality. Am J Obstet Gynecol 1991;164:47-52.

14. Fleischer AC, Kepple DR, Entman SS. Transvaginal sonography of uterine disorders. In: Timor-Tritsch and Rottem, editors. Transvaginal Sonography. New York: Elsevier; 1991; p 109-30.

15. Cagnazzo G, D’Addario U, Martinelli G, et al. Depth of myometrial invasion in endometrial cancer: preoperative assessment by transvaginal ultrasonography and magnetic resonance imaging. Ultrasound Obstet Gynecol 1992;2:40-43.

16. Fleischer AC, Dudley BS, Entman SS, et al. Myometrial invasion: sonographic assessment. Radiology 1987;162 :307-10.

17. Fleischer AC, Kalemeris GC, Machin JE, et al. Sonographic depiction of normal and abnormal endometrium with histopathologic correlation. J Ultrasound Med 1986; 5:445-52.

18. Tsuda H, Kawabata K, Yamamoto K, et al. Endometrial thickness as measured by transvaginal ultrasonography for identifying endometrial malignancy in postmenopausal women. Ultrasound Med Biol 1994;20:S248.

19. Dorum A, Kristensen B, Langebrekke A, et al. Evaluation of endometrial thickness measured by endovaginal ultrasound in women with postmenopausal bleeding. Acta Obstet Gynecol Scand 1993;72:116-119. 